\title{
Plasma fibronectin in normal subjects and in various disease states
}

\author{
NE STATHAKIS, A FOUNTAS, E TSIANOS \\ From the Professorial Medical Unit, Evangelismos Hospital, Athens, Greece
}

SUMIMARY Plasma fibronectin was determined in 121 normal adults and in 149 patients. Fibronectint levels in normals were strongly influenced by sex and age. The mean value of the protein in cancer: patients did not differ from that in normal controls; however, patients with cryofibrinogenaemia ori extensive liver metastases had lower values whereas those with obstructive jaundice due to pancreatic $\AA$ carcinoma had higher values than normal controls. Fibronectin levels were greatly increased in patients with primary biliary cirrhosis and moderately elevated in nephrotic syndrome. In patients with severe infection or sepsis, plasma fibronectin did not show a consistent pattern. Patients with overt disseminated intravascular coagulation, irrespective of its cause, had the lowest plasma fibronectin concentrations.

Fibronectin (also known as cold-insoluble globulin) is a glycoprotein with a molecular weight of 450000 . It is composed of two apparently identical subunits, which are held together with disulphide bonds. ${ }^{12}$ Fibronectin, which is a normal constituent of plasma, is also widely deposited in connective tissue, blood vessel walls, and basement membranes, being a major non-collagenous component of all organ stroma. Among its several properties of special interest are the following: it crosslinks with fibrin when blood clots through the action of fibrin stabilising factor $;^{3}$ it has an affinity for fibrin at both room and low temperatures ${ }^{4-6}$ while its affinity for fibrinogen is weak and evident only in the cold $;^{6}$ it binds to heparin and is the only protein precipitated by heparin at $+4^{\circ} ; ;^{7}$ it has a strong affinity and binds to denatured and, less actively, to native collagen $;^{8}$ it mediates the adhesion of fibroblasts to collagen;9 and it is a mediator of the attachment of denatured collagen to macrophages. ${ }^{10}$

The concentrations of plasma fibronectin in normal subjects and in various diseases have been determined in several laboratories. 11-15 However, some of the data reported are contradictory and inadequate for final conclusions to be drawn. In the present study, we report the results of fibronectin measurements in the plasma of 121 normal subjects and of 149 patients with various disease states.

Accepted for publication 30 September 1980

\section{Material and methods}

The clinical material studied included the following $\frac{2}{8}$ groups: (1) 121 normal subjects (61 men and 60F women), mostly blood donors; (2) 94 patients3 (60 men and 34 women) with advanced cancer This group included patients with cancer of the lung. (14), stomach (12), pancreas (16), colon (10), liver (8), ovaries (6), and miscellaneous other sites? (3) 24 patients with infection (pneumonia, pyelone-3. phritis, cellulitis) or sepsis (with both Gram-positiven. and Gram-negative bacteraemia) (14 men and $10 \%$ women); (4) five women with primary biliaryo cirrhosis. This diagnosis was confirmed in all cases? by liver biopsy; (5) 10 patients with nephrotio syndrome ( 5 men and 5 women). HistologicaF. examination of kidney biopsy material revealed membranous glomerulonephritis (6 cases), mem $\sim$ branoproliferative glomerulonephritis ( 2 cases) N focal glomerulonephritis (1 case), and amyloidosis ( 1 case); (6) 14 patients with overt disseminateck intravascular coagulation (DIC) secondary t\& carcinoma (5), acute leukaemia (4), and septicaemi市 (5). All these cases had decreased fibrinogen con:centration, thrombocytopenia, prolonged pro $-\frac{0}{\circ}$ thrombin and partial thromboplastin times, and increased fibrin degradation products.

PLASMA FIBRONECTIN DETERMINATIONS Fasting venous blood, collected by venepuncture 504 
with siliconised needles and plastic syringes, was added to a $1 / 10$ volume of $3.8 \%$ sodium citrate in silicone-coated tubes. Plasma was prepared by centrifugation at $2400 \mathrm{~g}$ for 20 minutes at room temperature; it was frozen at $-30^{\circ}$ and thawed just before assay.

Fibronectin concentration was determined by Laurell's electroimmunoassay ${ }^{16}$ in $1 \%$ agarose containing monospecific antiserum (a generous gift from Dr Mosesson, Downstate Medical Center, State University of New York, Brooklyn, USA). Electrophoresis was performed overnight at 90 volts

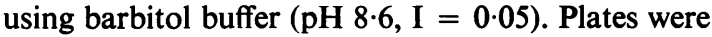
washed for 8-10 hours in tris-buffered saline and fixed in $1 \%$ tannic acid or squashed, dried, and stained with Coomassie brilliant blue.

Purified plasma fibronectin was prepared as previously described ${ }^{17}$ and served as a primary standard. The protein concentration of the purified protein was determined by absorbance at $280 \mathrm{~nm}$ by assuming absorption coefficient $\left(\mathrm{A}_{1 \mathrm{~cm}}^{1 \%}\right) 12 \cdot 8 .{ }^{1}$ The primary standard was used to determine the concentration of fibronectin in pooled citrated plasma from 20 normal adults. Portions of $1 \mathrm{ml}$ of the pooled plasma were stored at $-30^{\circ}$ and served as secondary standards. On each plate single applications of four dilutions of the secondary standard, together with double applications of one dilution of unknown plasma, were made.

\section{OTHER STUDIES}

For the detection of cryofibrinogenaemia, $2 \mathrm{ml}$ of fresh citrated plasma were incubated in a siliconecoated tube for 24 hours at $+4^{\circ}$. Positive cases formed a cryoprecipitate, which was not present in the serum of the same patient refrigerated under the same conditions.

Fibrinogen was determined by the method of Ratnoff and Menzie. ${ }^{18}$ The remainder of the coagulation tests were performed using standard techniques. ${ }^{19}$
Student's $t$ test was applied to calculate the significance of differences.

\section{Results}

PLASMA FIBRONECTIN IN NORMAL SUBJECTS The mean fibronectin concentration in the citrated plasma of 121 normal adults was $325 \pm 76 \mu \mathrm{g} / \mathrm{ml}$. The men had higher fibronectin plasma levels than the women $(P=0.05)$ (Table 1). The pattern of distribution of plasma fibronectin levels according to sex and age permitted the separation of the whole material into three age groups: $21-30$ years, $31-50$ years, and over 51 years. The mean value of each subgroup is shown in Table 2 . In both men and women, fibronectin was significantly lower in the 21-30 year group than in the older age groups. The fibronectin concentrations in men aged 31-50 and over 51 were similar, while the concentration of protein was lower in women aged 31-50 years than in women over 51 years, but this difference did not reach statistical significance.

Table 1 Fibronectin levels in normal subjects

\begin{tabular}{lrrl}
\hline & Number & Age (years) & $\begin{array}{l}\text { Fibronectin } \\
(\mu \mathrm{gg} / \mathrm{ml})\end{array}$ \\
\hline All normal subjects & 121 & $40 \cdot 5 \pm 17 \cdot 1$ & $325 \cdot 0 \pm 76 \cdot 0$ \\
Men & 61 & $40 \cdot 8 \pm 18 \cdot 3$ & $339 \cdot 4 \pm 70 \cdot 2^{*}$ \\
Women & 60 & $40 \cdot 2 \pm 16 \cdot 2$ & $311 \cdot 8 \pm 81 \cdot 5^{*}$ \\
\hline
\end{tabular}

*Men $v$ women: $t=1.99(\mathrm{P}=0.05)$.

Analysis of the data in women according to menopausal state showed that premenopausal women had less fibronectin $(284.6 \pm 71.9 \mu \mathrm{g} / \mathrm{ml})$ than postmenopausal women $(347 \cdot 8 \pm 84 \cdot 1 \mu \mathrm{g} / \mathrm{ml})$ $(\mathbf{P}<0.01)$. When plasma fibronectin levels of the three age groups were related to sex it was found that men aged $31-50$ years had significantly higher levels than women of the same age $(P<0.05)$. In the

Table 2 Fibronectin concentrations in normal subjects: distribution according to age and sex

\begin{tabular}{|c|c|c|c|c|c|c|}
\hline & \multicolumn{6}{|c|}{ Age groups (years) } \\
\hline & \multicolumn{2}{|c|}{$21-30$} & \multicolumn{2}{|c|}{$31-50$} & \multicolumn{2}{|c|}{$51-80$} \\
\hline & No & Fibronectin $(\mu g / m l)$ & No & Fibronectin $(\mu \mathrm{g} / \mathrm{ml})$ & No & Fibronectin $(\mu \mathrm{g} / \mathrm{ml})$ \\
\hline $\begin{array}{l}\text { All normal subjects } \\
\text { Men } \\
\text { Women }\end{array}$ & $\begin{array}{l}40 \\
21 \\
19\end{array}$ & $\begin{array}{l}284 \cdot 4 \pm 61 \cdot 1 \\
300 \cdot 1 \pm 61 \cdot 9 \\
267 \cdot 1 \pm 67 \cdot 6\end{array}$ & $\begin{array}{l}51 \\
25 \\
26\end{array}$ & $\begin{array}{l}340.1 \pm 79.2 \\
366.5 \pm 70.2 \\
316.8 \pm 80.4\end{array}$ & $\begin{array}{l}30 \\
15 \\
15\end{array}$ & $\begin{array}{l}354.8 \pm 75.3 \\
349.6 \pm 58.6 \\
360.0 \pm 91.0\end{array}$ \\
\hline
\end{tabular}

Statistically significant $t$-test values:

All subjects 21-30 yr $v$ all subjects 31-50 yr: $t=3.79(\mathrm{P}<0.01)$

Men 21-30 yr $v$ men 31-50 yr: $t=3.40(\mathrm{P}<0.01)$

Women $\quad 21-30 \mathrm{yr} v$ women $\quad 31-50 \mathrm{yr}: t=2.24(\mathrm{P}<0.05)$

Men $\quad 31-50 \mathrm{yr} v$ women $31-50 \mathrm{yr}: t=2.34(\mathrm{P}<0.05)$ 
other age groups there were no significant differences in fibronectin levels between the two sexes.

PLASMA FIBRONECTIN IN CANCER PATIENTS The mean fibronectin concentration in cancer patients did not differ from that of matched normal controls (Table 3). However, of the patients, 19 had fibronectin concentrations above ( 7 patients) or below (12 patients) the normal limits.

Table 3 Plasma fibronectin levels in patients with advanced cancer

\begin{tabular}{llll}
\hline Group & No & Age $($ years $)$ & Fibronectin $(\mu \mathrm{g} / \mathrm{ml})$ \\
\hline All patients with cancer & 94 & $60.3 \pm 11 \cdot 4$ & $348 \cdot 0 \pm 121 \cdot 0$ \\
All controls & 48 & $57.4 \pm 13 \cdot 9$ & $350 \cdot 0 \pm 74 \cdot 7$ \\
Male patients & 60 & $61 \cdot 2 \pm 10 \cdot 6$ & $344 \cdot 1 \pm 125 \cdot 3$ \\
Matched controls & 31 & $58 \cdot 7 \pm 16 \cdot 3$ & $353 \cdot 5 \pm 64 \cdot 8$ \\
Female patients & 34 & $58.3 \pm 12 \cdot 1$ & $356 \cdot 7 \pm 111 \cdot 2$ \\
Matched controls & 17 & $55.0 \pm 11 \cdot 3$ & $343 \cdot 6 \pm 84.3$ \\
\hline
\end{tabular}

The origin of the cancer (evaluated in carcinoma of the lung, stomach, pancreas, colon, ovaries, and liver) did not influence the fibronectin concentration. In contrast, fibronectin levels were influenced by some complications of the disease. As shown in Table 4, patients with cryofibrinogenaemia had a small but significant decrease in fibronectin levels. In addition, patients with extensive neoplastic infiltration of the liver had low plasma fibronectin whereas the protein was significantly elevated in patients with obstructive jaundice due to carcinoma of the pancreas (Table 5).

Table 4 Plasma fibronectin in cancer patients with or without cryofibrinogenaemia

\begin{tabular}{|c|c|c|c|}
\hline Cryofibrinogenaemia & No & $\operatorname{Age}(y r)$ & Fibronectin $(\mu \mathrm{g} / \mathrm{ml})$ \\
\hline $\begin{array}{l}(+) \\
(-)\end{array}$ & $\begin{array}{l}11 \\
83\end{array}$ & $\begin{array}{l}55.8 \pm 11.5 \\
60.7 \pm 11.4\end{array}$ & $\begin{array}{l}282.2 \pm 110.2 \\
357.5 \pm 115.4^{*}\end{array}$ \\
\hline
\end{tabular}

*Patients (+) v patients $(-): t=2.12(\mathrm{P}<0.05)$.

Table 5 Plasma fibronectin in cancer patients with extensive liver metastases or cholestasis

\begin{tabular}{lrll}
\hline Group & No Age $(\mathrm{yr})$ & Fibronectin $(\mu \mathrm{g} / \mathrm{ml})$ \\
\hline $\begin{array}{l}\text { Cancer patients with } \\
\begin{array}{l}\text { extensive liver } \\
\text { metastases }\end{array}\end{array}$ & 10 & $62.6 \pm 10.0$ & $259 \cdot 8 \pm 79.9^{*}$ \\
$\begin{array}{l}\text { Patients with obstructive } \\
\text { jaundice secondary to }\end{array}$ & & \\
$\begin{array}{l}\text { pancreatic carcinoma } \\
\text { Controls }\end{array}$ & 98 & $58 \cdot 7 \pm 11.7$ & $444 \cdot 6 \pm 81.6 \dagger$ \\
\hline
\end{tabular}

*Patients $v$ controls: $t=3.28(\mathrm{P}<0.01)$.

†Patients $v$ controls: $t=3.98$ (P $<0.001)$.
FIBRONECTIN IN SEVERE INFECTIONS AND SEPSIS, PRIMARY BILIARY CIRRHOSIS, AND NEPHROTIC SYNDROME (Table 6)

The mean fibronectin concentration of patients with severe infections and sepsis did not differ from that of $\frac{}{0}$ matched normal controls. However, among the $\overline{\overline{\bar{\rho}}}$ patients nine had decreased and one increased values. $\stackrel{\oplus}{\circ}$

In patients with primary biliary cirrhosis fibronectin levels were significantly elevated $(P<0.001)$.

A small but significant elevation of fibronectin? was also found in patients with nephrotic syndrome $\overrightarrow{\vec{A}}$ $(P<0.05)$.

Table 6 Plasma fibronectin in patients with severe infection or sepsis, primary biliary cirrhosis, and nephrotic syndrome

\begin{tabular}{|c|c|c|c|}
\hline Group & No & Age (years) & Fibronectin $(\mu \mathrm{g} / \mathrm{ml})$ \\
\hline $\begin{array}{l}\text { Severe infections and } \\
\text { sepsis } \\
\text { Matched controls }\end{array}$ & $\begin{array}{l}24 \\
15\end{array}$ & $\begin{array}{l}52.7 \pm 12.6 \\
50.4 \pm 11.6\end{array}$ & $\begin{array}{l}284 \cdot 4 \pm 183 \cdot 6^{*} \\
346.4 \pm 83.2\end{array}$ \\
\hline $\begin{array}{l}\text { Primary biliary cirrhosis } \\
\text { Matched controls }\end{array}$ & $\begin{array}{l}5 \\
8\end{array}$ & $\begin{array}{l}45 \cdot 4 \pm 7 \cdot 9 \\
45 \cdot 3 \pm 7 \cdot 4\end{array}$ & $\begin{array}{l}630 \cdot 8 \pm 136 \cdot 0 \dagger \\
332 \cdot 5 \pm 49 \cdot 7\end{array}$ \\
\hline $\begin{array}{l}\text { Nephrotic syndrome } \\
\text { Matched controls }\end{array}$ & $\begin{array}{l}10 \\
12\end{array}$ & $\begin{array}{l}42 \cdot 4 \pm 13 \cdot 6 \\
44 \cdot 1 \pm 12 \cdot 2\end{array}$ & $\begin{array}{l}443.0 \pm 127 \cdot 0 \ddagger \\
332.0 \pm 64 \cdot 2\end{array}$ \\
\hline
\end{tabular}

${ }^{*} t=1.4(\mathrm{P}>0.05)$.

$t t=4.7(\mathrm{P}<0.001)$.

$\ddagger t=2.5(\mathrm{P}<0.05)$.

FIBRONECTIN IN OVERT DISSEMINATED INTRAVASCULAR COAGULATION (DIC)

The mean value of fibronectin was much lower in? patients with DIC $(107 \pm 66.6 \mu \mathrm{g} / \mathrm{ml})$ than in corresponding normal controls $(336 \pm 71 \cdot 0 \mu \mathrm{g} / \mathrm{ml})$ (P $<0.001$ ). In 14 out of 16 patients studied, fibro-? nectin levels were lower than the lower limits of 3 normal.

\section{Discussion}

The results of the present study indicate that plasmao fibronectin concentrations in normal adults are strongly influenced by sex and age. Men had higher $\sim$ fibronectin concentrations than women. This finding, $N$ which confirms previous observations, ${ }^{11} 12$ was N significant only for the age group 31-50 years. $\sigma$ Women under 30 tended to have lower values whereas those over 50 years did not differ from the men. Both men and women showed a significant@ increase in fibronectin concentrations from the third to the fourth decade of life. In addition, premenopausal women had lower fibronectin levels $\vec{\Phi}$ than postmenopausal women. Although these $\frac{\mathcal{O}}{\mathbb{D}}$ complex relations of fibronectin levels to sex and age $\frac{}{\rho}$ imply hormonal influences, it is very likely that othere factors may play an important role. In any event, $\delta$ 
these variations in plasma fibronectin must be taken into consideration in any study on the behaviour of this protein in various disease states.

There is little information concerning plasma fibronectin in patients with cancer. Bruhn and Heimburger ${ }^{13}$ reported normal levels in an unstated number of patients with malignancies. In the present study, although the mean value of plasma fibronectin in patients with advanced cancer did not differ from that of the matched controls, $20 \%$ of the patients had fibronectin concentrations above or below the normal limits. This may indicate that among cancer patients there are subgroups with abnormally high or low plasma fibronectin levels. Interesting in this respect are the results of Mosher and Williams, ${ }^{12}$ who found that although fibronectin was elevated in a small number of patients with metastatic breast carcinoma, it was decreased in severely ill patients with cancer. Analysis of our data revealed that the site of origin did not influence plasma fibronectin, at least for the carcinomas of the lung, stomach, liver, pancreas, and ovaries, for which an adequate number of patients was studied. In contrast, fibronectin levels were related to some complications of the disease, namely, obstructive jaundice, cryofibrinogenaemia, and extensive liver metastases. The low values found in the last group of patients corroborate the results of Mosher and Williams $^{12}$ that this protein is decreased in severely ill patients.

The relatively low fibronectin levels in patients with cryofibrinogenaemia may be due to enhanced catabolism of the protein secondary to intravascular fibrin formation. Fibronectin complexes with fibrin both in vitro ${ }^{5} 6$ and in vivo. ${ }^{20}$ These complexes, which precipitate in the cold in vitro, are rapidly cleared from the blood in vivo. As a result, fibronectin levels are usually very low in overt DIC, ${ }^{21}$ a finding confirmed in the present study. In cryofibrinogenaemic cancer patients without overt DIC, fibronectin levels are intermediate between normal and those in overt DIC.

Patients with obstructive jaundice due to pancreatic carcinoma had slightly elevated plasma fibronectin. Forkman et al. ${ }^{14}$ reported very high levels in patients with recurrent cholestasis of pregnancy. Similarly, we found that the protein was elevated in patients with primary biliary cirrhosis. It appears, therefore, that an increased plasma fibronectin concentration is a general characteristic of cholestasis irrespective of its aetiology. A slight but significant elevation of fibronectin levels also seems to characterise nephrotic syndrome.

Plasma fibronectin did not follow a consistent pattern in patients with severe infection or sepsis. Mosher $^{22}$ found a significant decrease in plasma fibronectin in severely ill monkeys with experimental Rocky Mountain spotted fever which he attributed to fibronectin and fibrin deposition and lysis in infected blood vessels. However, he did not find any change in experimentally induced Salmonella typhi and Streptococcus pneumoniae bacteraemia. These observations in animals may explain our results in clinical material where a great range of values was obtained.

\section{References}

${ }^{1}$ Mosesson MW, Umfleet RA. The cold insoluble globulin of human plasma. I. Purification, primary characterization and relationship to fibrinogen and other coldinsoluble fraction components. J Biol Chem 1970; 245:5728-36.

2 Mosesson MW, Chen AB, Huseby RM. The cold insoluble globulin of human plasma: studies of its essential structural features. Biochim Biophys Acta 1975;386: 509-24.

${ }^{3}$ Mosher DF. Cross-linking of cold-insoluble globulin by fibrin stabilizing factor. J Biol Chem 1975;250:6614-21.

${ }^{4}$ Ruoslahti E, Vahesi A. Interaction of soluble fibroblast surface antigen with fibrinogen and fibrin. Identity with cold-insoluble globulin of human plasma. J Exp Med $1975 ; 141: 497-501$.

${ }^{5}$ Stemberger A, Hörmann H. Affinity chromatography on immobilized fibrinogen and fibrin monomer. II. The behaviour of cold-insoluble globulin. Hoppe-Seyler's Z Physiol Chem 1976;357:1003-5.

- Stathakis NE, Mosesson MW, Chen AB, Galanakis DK. Cryoprecipitation of fibrin-fibrinogen complexes induced by the cold-insoluble globulin of plasma. Blood 1978; 51:1211-22.

' Stathakis NE, Mosesson MW. Interactions among heparin, cold-insoluble globulin and fibrinogen in formation of the heparin precipitable fraction of plasma. $J$ Clin Invest 1977;60:855-65.

${ }^{8}$ Ruoslahti E, Engvall E. Immunochemical and collagenbinding properties of fibronectin. Ann NY Acad Sci 1978;312:178-91.

- Gold LI, Pearlstein E. Fibronectin-collagen binding and requirements during cellular adhesion. Biochem $J$ 1980;186:551-9.

${ }^{10}$ Hörmann H, Jelinic V. Fibronectin. VII. Binding of coldinsoluble globulin and denatured collagen by macrophages. Hoppe-Seyler's Z Physiol Chem 1980;361: 379-87.

${ }^{11}$ Fyrand D, Solum NO. Studies on cold-insoluble globulin in dermatological patients. I. Immunochemical quantitation in citrated plasma from patients with increased amounts of heparin precipitable fraction (HPF). Thromb Res 1976;9:447-55.

12 Mosher DF, Williams EM. Fibronectin concentration is decreased in plasma of severely ill patients with disseminated intravascular coagulation. $J$ Lab Clin Med $1978 ; 91: 729-35$.

${ }^{13}$ Bruhn HD, Heimburger N. Factor-VIII-related antigen and cold-insoluble globulin in leukaemias and carcinomas. Haemostasis 1976;5:189-92.

14 Forkman B, Ganrot PO, Gennser G, Rannevik G. Plasma protein pattern in recurrent cholestasis of pregnancy. Scand J Clin Lab Invest 1972;29 (Suppl 124):89-96.

15 Ganrot PO. Variation of the concentrations of some plasma proteins in normal adults, in pregnant women and in newborns. Scand J Clin Lab Invest 1972;29 (Suppl 
124):83-93.

${ }^{16}$ Laurell C-B. Electro-immunoassay. Scand J Clin Lab Invest 1972;29 (Suppl 124):21-37.

${ }^{17}$ Chen AB, Mosesson MW. An improved method for purification of the cold insoluble globulin of human plasma (CIg). Anal Bioch 1977;79:144-9.

18 Ratnoff OD, Menzie C. New method for determination of fibrinogen in small samples of plasma. J Lab Clin Med 1951;37:316-20.

19 Dacie JV, Lewis SM. Practical haematology, 5th ed. Edinburgh, London, and New York: Churchill Livingstone, 1975.

${ }^{20}$ Sherman LA, Lee J. Fibronectin: its blood clearance and interaction with fibrin in vivo. Thromb Halmost 1979; 42:121.

${ }^{21}$ Matsuda M, Yoshida N, Aoki N, Watabayashi K. Dis tribution of cold-insoluble globulin in plasma and tissues. Ann NY Acad Sci 1978;312:74-92.

${ }^{22}$ Mosher DF. Changes in plasma cold-insoluble globulin concentration during experimental Rocky Mountain spotted fever infection in rhesus monkeys. Thromb Res 1976;9:37-45.

Requests for reprints to: Dr NE Stathakis, Department of Medical Oncology, St Bartholomew's Hospital, London EC1A 7BE, England. 